\title{
PENERAPAN EMERGENCY SYSTEM BERBASIS MOBILE (STUDY KASUS INSTITUT TEKNOLOGI TELKOM PURWOKERTO)
}

\author{
Aditya Wijayanto $^{\# 1}$, Fahrudin Mukti $\mathrm{W}^{* 2}$ \\ \# Fakultas Teknologi Industri dan Informatika, Institut Teknologi Telkom Purwokerto \\ Jl. D.I Panjaitan 128 Purwokerto, Jawa Tengah, Indonesia \\ ${ }^{1}$ aditya.wijayanto@ittelkom-pwt.ac.id \\ ${ }^{2}$ fahrudin@ittelkom-pwt.ac.id
}

Accepted on May 14, 2019

\begin{abstract}
Abstrak
Keamanan kampus Institut Teknologi Telkom Purwokerto merupakan salah satu faktor utama di dalam terciptanya kenyamanan dan keamanan. Emergency condition merupakan persoalan yang berdampak langsung pada aspek pelayanan, bahkan Emergency condition bersinggungan langsung dengan keselamatan diantaranya: kesehatan, kecelakaan, dan perilaku sosial. Keamanan selama berkegiatan di kawasan kampus Institut Teknologi Telkom Purwokerto menjadi perhatian utama. Untuk mengantisipasi tindak kriminalitas, antara lain pencurian, dengan inovasi teknologi terinspirasi dari Aplikasi Panic Button yang telah digunakan pihak kepolisian. Penelitian ini bertujuan bagaimana menggunakan teknologi smartphone android sebagai cara menekan tindak kriminalitas dan masalah-masalah keamanan yang ada di Institut Teknologi Telkom Purwokerto. Dengan pembuatan aplikasi berbasis Android ini pihak keamanan kampus dapat memonitoring keamanan lingkungan kampusnya secara lebih efisien dan menciptakan rasa aman kepada seluruh civitas akademika di Institut Teknologi Telkom Purwokerto. Aplikasi keamanan kampus ini berbasis mobile yang memiliki sistem operasi android, terdapat aplikasi yang diinstall pada keamanan kampus dan aplikasi yang diinstall oleh civitas akademika Institut Tenologi Telkom Purwokerto. Ketika terjadi tindak kriminalitas dan pihak keamanan kampus dapat segera memberikan respon menuju tempat lokasi terjadinya kriminalitas dengan cepat dan tepat.
\end{abstract}

Keywords: Emergency, System, Mobile, Keamanan, Kampus

\section{PENDAHULUAN}

$\mathrm{S}_{\mathrm{d}}$ ituasi darurat (emergency condition) adalah situasi yang memerlukan tanggapan yang harus disampaikan dengan kecepatan yang sesuai dengan kebutuhan kondisi tersebut. Emergency condition terkadang tidak berbanding lurus dengan pemberian respon yang diperlukan untuk menanggulanginya. Hal seperti ini sering terjadi pada kota - kota besar, tempat keramaian, bahkan di area kampus khusunya IT Telkom Purwokerto, terutama daerah atau tempat yang tidak mempunyai pelayanan akses pendukung jaringan komunikasi yang baik dalam infrastrukturnya [1]. 
Emergency condition merupakan persoalan yang berdampak langsung pada aspek pelayanan, bahkan Emergency condition bersinggungan langsung dengan keselamatan, diantaranya : kesehatan, kecelakaan, dan perlilaku sosial [2]. Tingkat respon Emergency condition yang rendah dapat menghambat seluruh aktivitas baik perkuliahan jika di kampus, bahkan perekonomian maupun aspek lainnya. Banyak orang mulai sadar akan bahaya di sekitar yang bisa datang tanpa diduga dan aplikasi untuk menangani situasi tersebut memang dibutuhkan. Maka dari itu kita perlu mempersiapkan diri dengan cara membawa alat perlindungan diri atau semacamnya. Salah satu cara adalah dengan memanfaatkan teknologi yang sudah melekat dengan kehidupan masyarakat saat ini yaitu Smartphone. Smartphone saat ini telah dilengkapi macam - macam aplikasi yang dapat digunakan untuk berbagai macam kegunaan dan dapat dengan mudah diunduh oleh penggunanya.

Penulis mencoba untuk memberikan solusi menyelesaikan masalah keamanan menggunakan teknologi informasi, untuk memonitor secara langsung keamanan di lingkungan kampus dapat berjalan dengan baik. Menggunakan aplikasi berbasis android diharapkan adanya tindakan respon secara cepat dari pihak keamanan kampus sehingga terciptanya keamanan di lingkungan Insitut Teknologi Telkom Purwokerto. Menggunakan android studio sebagai software untuk membuat sebuah prototype aplikasi berbasis android yang dapat digunakan para civitas akademika seperti pegawai, dosen mapupun mahasiswa dengan mudah menggunakan aplikasi yang ada pada smarphone mereka masing-masing. Tombol Bantuan Keamanan Institut Teknologi Telkom Purwokerto adalah aplikasi berbasis Android yang dirancang untuk merespon secara cepat apabila terjadi gangguan keamanan di lingkungan kampus. Aplikasi ini mendukung terciptanya keamanan kampus yang lebih kondusif.

\section{TINJAUAN PUSTAKA}

Aplikasi Emergency System dibuat sebagai salah satu cara persiapan menghadapi bahaya yang senantiasa bisa datang, dengan cara aplikasi sewaktu - waktu diaktifkan tanpa perlu melihat layar dan bisa melakukan serangkaian proses termasuk mengirimkan sms, menitikberatkan pada pencegahan kriminalitas [3]. Aplikasi Automatic Emergency System, menyelesaikan permasalahan masih lambannya respon system pelayanan public di Kota Tangerang terhadap masyarakat yang mengalami keadaan darurat atau keadaan yang memerlukan penanganan secara cepat, seperti sakit, kecelakaan dan kebakaran. Menitikberatkan pada kecepatan pemberian informasi kepada pihak - pihak yang terkait, seperti rumah sakit, kepolisian, dan pemadam kebakaran [1].

Aplikasi android dengan layanan berbasis lokasi (Location Based Service Aplication) yang memungkinkan pengguna untuk mengakses peta perjalanan posisi entity secara realtime, serta inovasi penggunaan Threat Button untuk mengirimkan notifikasi kepada sesama pengguna aplikasi. Menitikberatkan pada pemberian informasi secara real time tentang lokasi pengguna aplikasi dan pemberian informasi kepada sesama pengguna aplikasi [4]. Dari hal tersebut di atas dapat dilakukan sebuah penelitian tentang penerapan Emergency System berbasis Mobile yang dapat diterapkan di lingkungan Institut Teknologi Telkom, masih banyaknya permasalahan yang memerlukan bantuan pihak lain dalam penyelesaian masalah, namun masih belum adanya jalur komunikasi yang tepat.

\section{METODE PENELITIAN}

Penelitian ini termasuk ke dalam penelitian Research and Development ( $\mathrm{R} \& \mathrm{D})$. Metode penelitian ini digunakan untuk menghasilkan produk tertentu dan mengkaji keefektifan produk tersebut. Research and Development merupakan suatu proses atau langkah - langkah untuk mengembangkan suatu produk baru atau menyempurnakan produk yang telah ada yang dapat dipertanggungjawabkan. Produk tersebut tidak selalu berbentuk benda atau perangkat keras seperti buku, tetapi dapat juga berupa perangkat lunak atau program komputer, model pendidikan, pembelajaran atau pelatihan [5]. 


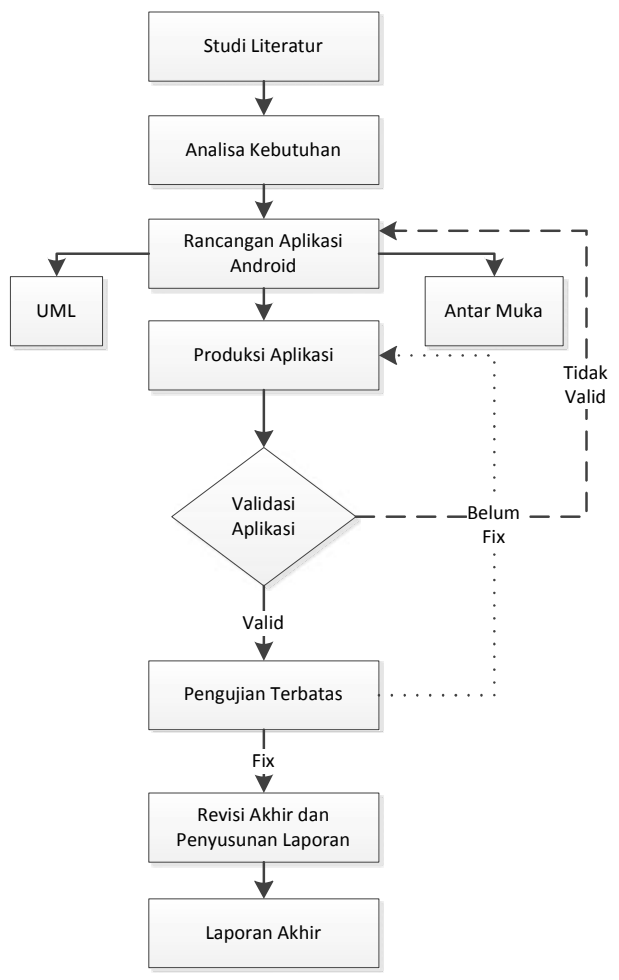

Gambar 1. Metode Penelitian

\section{A. Analisis Kebutuhan}

Analisis Kebutuhan Fungsional

Aplikasi mampu mengirimkan pesan Emergency, jenis gangguan, dan lokasi pengiriman pesan

Analisis Kebutuhan Non Fungsional

Analisis Perangkat Keras atau Hardware

1. Analisis Perangkat Keras atau Hardware

2 Unit Hp dengan spesifikasi sebagai berikut :
a. Prosesor
: Quad-core
b. Memori RAM : $2 \mathrm{~GB}$
c. Battery Capacity : 3000-3999 mAh
d. Sistem Operasi : Android 8.0 Oreo

2. Analisis Perangkat Lunak atau Software

Perangkat lunak (Software) yang digunakan adalah sebagai berikut :

a. Sistem Operasi : Windows 8.0

b. Software Lainnya: Andorid Studio

3. Analisis Pengguna atau User

User terdiri dari Security bagian keamanan dan Civitas Akademik Institut Teknologi Telkom Purwokerto. 


\section{B. Use Case Diagram}

Pada Use Case diagram, aplikasi tombol bantuan kampus ini memiliki 2 pengguna yaitu civitas akademika dan tim emergency system, lebih jelasnya dapat dilihat Gambar 2, dibawah ini:

Gambar 1 menjelaskan bahwa Civitas Akademik dan Tim Emergency System mempunyai tugas utama terdiri dari:

1. Hak akses untuk melakukan login ke webserver aplikasi

2. Melakukan isi data input keterangan dan input lokasi

3. Tim Emergency System menerima pesan alert dari civitas akademik

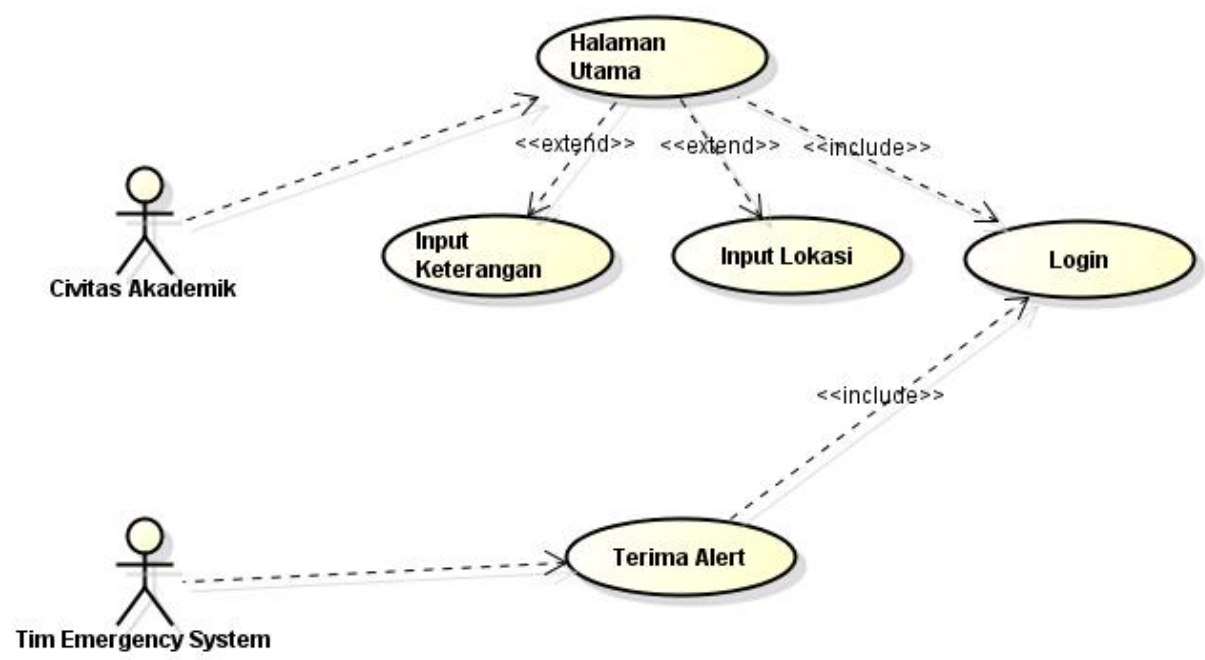

Gambar 2. Use Case Diagram Civitas Akademik dan Tim Emergency System

\section{Squence Diagram}

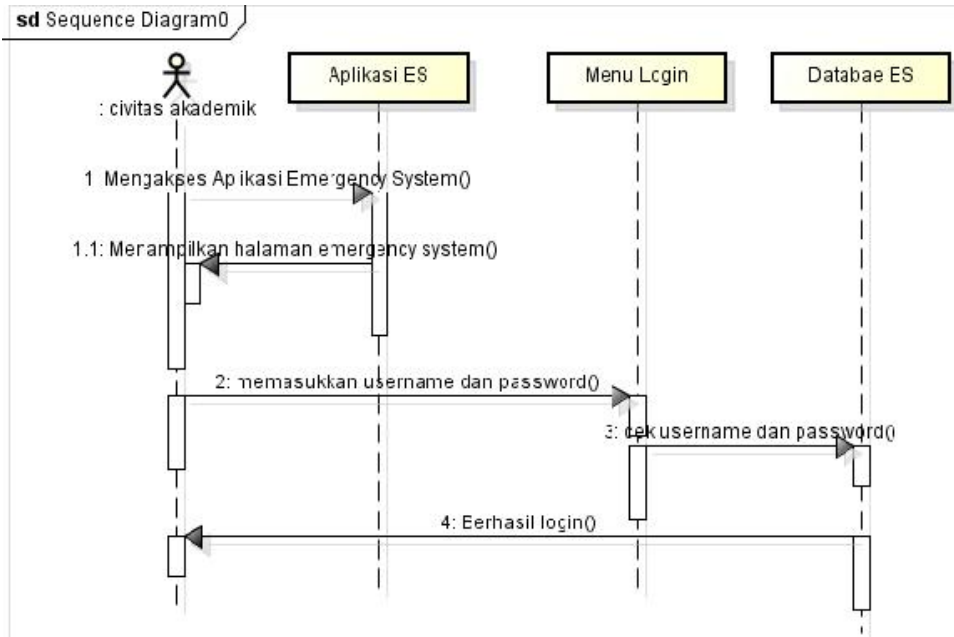

Gambar 3. Squence Diagram Login Emergency System 
sd Sequence Diagram1

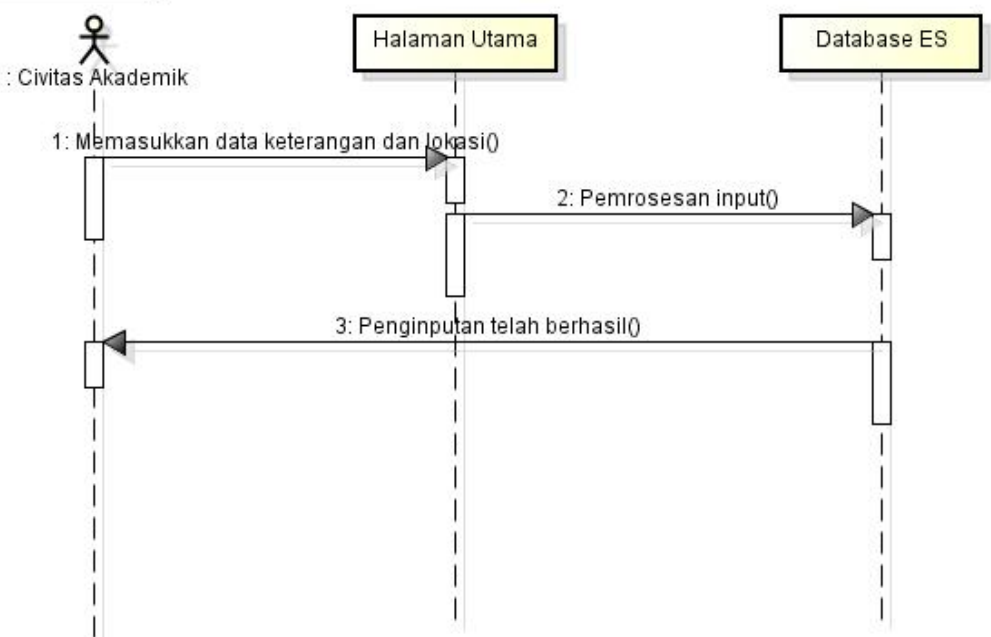

Gambar 3. Squence Diagram Menjalankan Aplikasi Emergency System

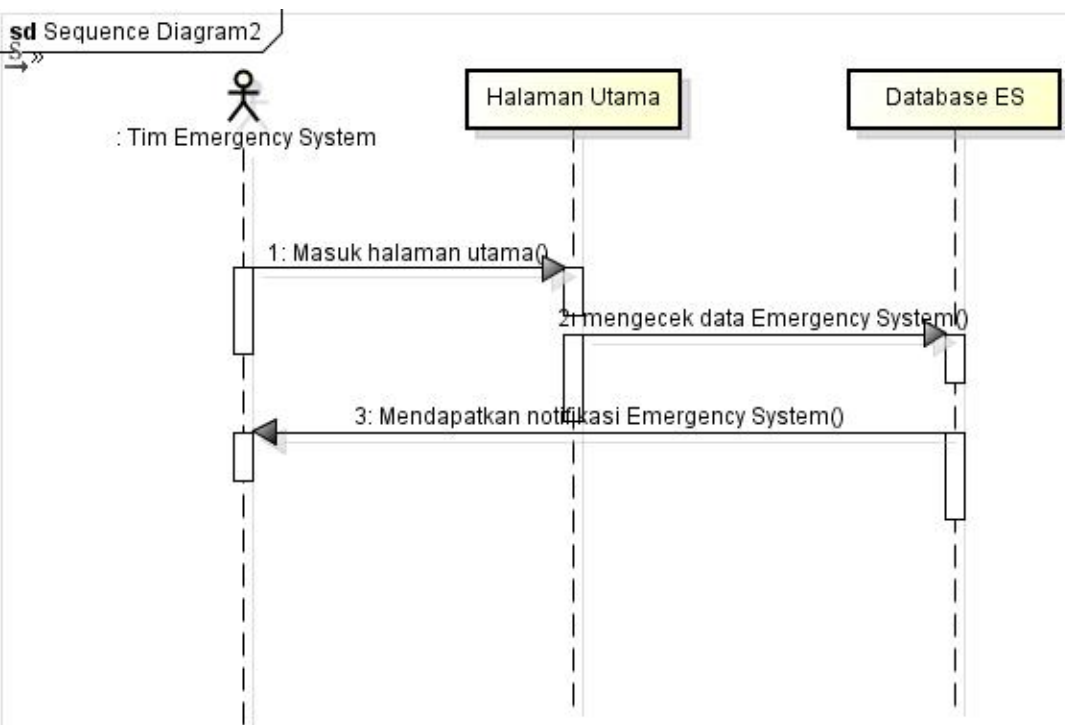

Gambar 4. Squence Diagram mengecek notifikasi Aplikasi Emergency System 


\section{HASIL DAN PEMBAHASAN}

Gambar 5 adalah halaman tampilan login aplikasi Emergency System. Untuk dapat menggunakan fitur tombol bantuan user diharuskan login terlebih dahulu, selanjutnya user akan dibawa ke halaman utama.

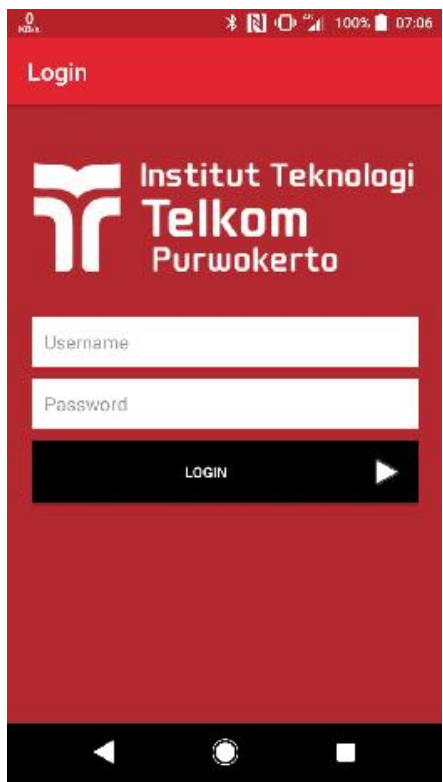

Gambar 5. Halaman Login Apliasi Emergency System

: $10: 57$ ans
Home

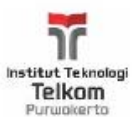

Send an Alert

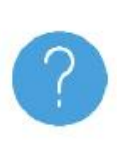

Informasi

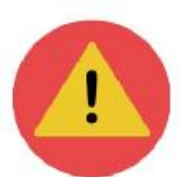

Emergency

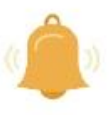

Alarm

Gambar 6. Halaman Utama Aplikasi Emergency System

Aplikasi tombol Emergency System pada Gambar 6 dapat diakses dengan menekan gambar merah dan memiliki tanda seru. Aplikasi akan menampilkan halaman berisi Team Emergency system yang dituju, keterangan dan lokasi seperti yang terdapat pada Gambar 7. 


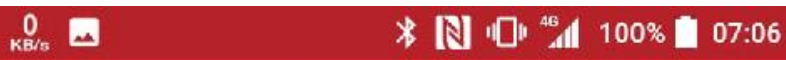

\section{Buat Alarm}

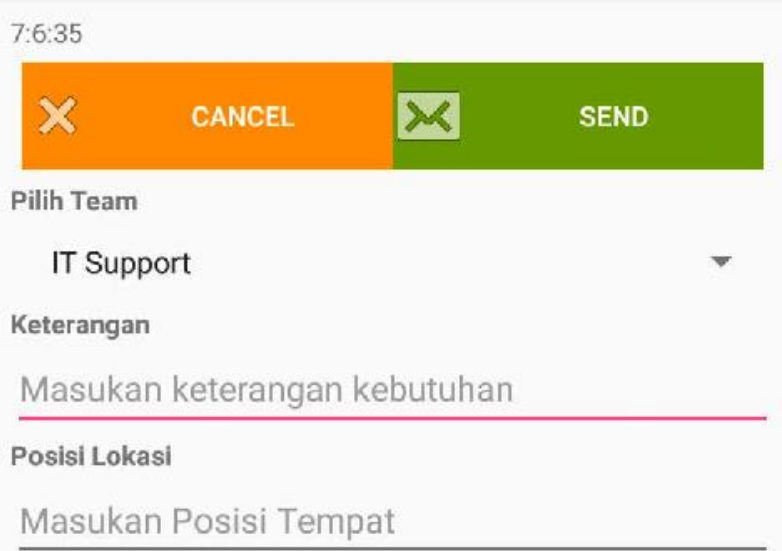

Gambar 7. Halaman Buat Alarm Aplikasi Emergency System

Gambar 7 adalah untuk membuat Alarm dengan memasukkan team yang akan dihubungi, keterangan tentang kebutuhan atau kendala yang dihadapi, dan memasukkan lokasi atau tempat user berada.

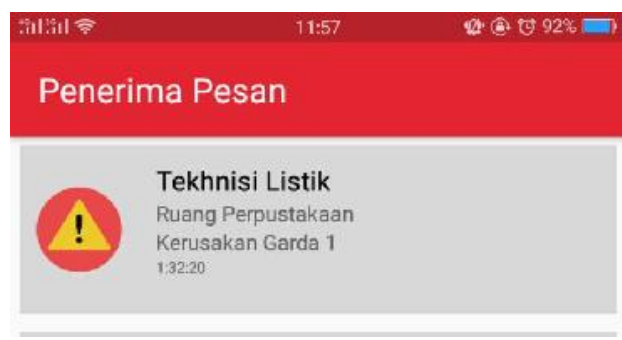

Gambar 8. Halaman Menerima Pesan Emergency System

Gambar 8 merupakan tampilan menerima pesan yang telah dikirimkan oleh user, pada HP security, IT Support, dan Teknisi akan keluar notifikasi seperti alarm. Alarm tidak akan berhenti sampai bagian security, IT Support, dan Teknisi membuka aplikasi Emergency System

\section{KESIMPULAN}

Berdasarkan hasil penelitian yang dilakukan maka dapat diambil kesimpulan telah dihasilkan Emergency system Institut Teknologi Telkom Purwokerto untuk menjaga lingkungan kampus yang kondusif dari segi keamanan dan kegiatan belajar mengajar. Emergency System ini juga memudahkan bagi Tim Emergency System dalam merespon adanya tindakan kejahatan ataupun hal - hal yang mengganggu keberlangsungan kegiatan belajar mengajar.

Aplikasi ini kedepannya terdapat fitur - fitur tambahan seperti tersinkronisasi dengan aplikasi bantuan yang dimiliki pihak kepolisian. Perlu adanya perbaikan pada database server agar lebih stabil. Perlu adanya pengujian aplikasi agar terlihat bug dan error pada Aplikasi Emergency System. 


\section{REFERENCES}

[1] Henderi, dkk., 2016. Rancang Bangun Automatic Emergency System Berbasis Mobile. Tangerang : STMIK Raharja

[2] Rahmawati, H, 2014. Bencana di Indonesia dan Pergeseran Paradigma Penanggungan Bencana. [Online].Availabe at: http://tarjih.muhammadiyah.or.id/muhfile/tarjih/download/PenguranganResiko Bencana_Rahmawati.pdf.[Accessed 22 Februari 2016].

[3] Purnomo, Rizky., Richard, Beeh, Y., 2016, Perancangan Aplikasi Emergency Button berbasis Android. Salatiga:Universitas Kristen Satya Wacana

[4] Rahman Kautsar Alvin, dkk., 2016, Partmaps : Penerapan Teknologi Location Based Service dan Threat Button pada Aplikasi Android. Surabaya : Institut Teknologi Sepuluh Nopember

[5] Jati Setyadi H., 2018. Aplikasi Tombol Bantuan Keamanan Kampus Universitas Mulawarman Samarinda Berbasis Mobile Android. Samarinda: Universitas Mulawarman Samarinda 